\title{
Applying Design Research Artifacts for Building Design Research Artifacts: A Process Model for Enterprise Architecture Planning
}

\author{
Stephan Aier and Bettina Gleichauf \\ Institute of Information Management \\ University of St. Gallen \\ Müller-Friedberg-Str. 8 \\ CH-9000 St. Gallen \\ \{stephan.aier, bettina.gleichauf\}@unisg.ch
}

\begin{abstract}
Enterprise architecture (EA) describes the fundamental structure of an organization from business to IT. EA as a practice as well as a research topic has been around for several years. However, existing methods largely neglect the existence of time which is essential in order to systematically approach EA planning. The article at hand builds a process model for EA planning as a design research artifact. We therefore use another more general design research artifact - a method for process engineering - in order to systematically build our proposed planning process. From a design science research (DSR) perspective we demonstrate how elements of the DSR knowledge base can be applied to create new DSR artifacts and how DSR might build a toolbox as it is available in other mature engineering disciplines.
\end{abstract}

Keywords: enterprise architecture, planning, process design.

\section{Introduction}

Design science research (DSR) deals with the design of useful $\operatorname{artifacts}^{1}[1,5,6]$ for relevant problems [3] as well as with research on DSR itself $[3,7,8]$. The primary goal of the paper at hand is to create a useful artifact and to demonstrate the execution of a DSR process while doing so. A secondary goal of the paper is to demonstrate the employment of a more general DSR artifact in a design research (DR) process which finally leads to a discussion of the necessity of a structured DSR body of knowledge as it is available in mature engineering disciplines.

Our artifact construction aims at the field of enterprise architecture (EA). The ANSI/IEEE Standard 1471-2000 defines architecture as "the fundamental organization of a system, embodied in its components, their relationships to each other and the

1 In literature there is some agreement on the artifact types of constructs, models, and methods [1-3]. In some cases also instances are considered DSR artifacts while e.g. Gregor and Jones state "that 'constructs, models and methods' are all one type of thing and can be equated to theory or components of theory, while instantiations are a different type of thing altogether" [4].

R. Winter, J.L. Zhao, and S. Aier (Eds.): DESRIST 2010, LNCS 6105, pp. 333-348, 2010.

(C) Springer-Verlag Berlin Heidelberg 2010 
environment, and the principles governing its design and evolution" [9]. Most authors agree that EA targets a holistic scope and therefore provides a broad and aggregate view of an entire corporation or government agency [10] covering strategic aspects, organizational structure, business processes, software and data, as well as IT infrastructure [11-14]. EA management can provide systematic support to organizational change that affects business structures as well as IT structures by providing constructional principles for designing the enterprise [15]. A suitable degree of formalization is needed in order to ensure traceable and repeatable results. Furthermore (semi) formalized models and sound methods are needed to enable division of labor among heterogeneous stakeholder groups [16, 17].

However, so far EA modeling has been restricted to modeling of (dateless) states of an enterprise by the majority of contributions $[18,19]$. EA did not address the modeling of transformation and thus of the engineering process itself. Therefore this paper aims at answering the following research question: Which activities should be performed for EA planning and how can these activities be structured in an EA planning process? To answer this question our core contribution is an EA planning process which builds the foundation of an EA planning method. In order to systematically build this process we will apply another DR artifact - PROMET BPR [20]. PROMET $\mathrm{BPR}$ is a method for the (re-)design of business processes in general.

Scientific literature provides a number DSR procedure models [1, 3, 21, 22]. Specifically we follow the "identify a need-build-evaluate-learn and theorize" approach by Rossi and Sein [21]. We identify the need and define the objectives of our artifact by analyzing current practitioners' solutions and by analyzing related work (section 2). In section 3 we briefly introduce PROMET BPR and in section 4 we apply PROMET BPR for the construction our artifact. In section 5 we summarize an industry case which serves as an evaluation of our artifact. Finally in section 6 we reflect our solution and discuss the findings from a DSR perspective.

\section{Identify the Need for EA Planning}

In order to identify the need for a sound EA planning process we will discuss two industry cases for a practitioners' perspective first (section 2.1). Then we will discuss existing contributions from literature for an academics' perspective (section 2.2).

\subsection{Practitioners' Needs}

The following case studies exemplify how EA planning is currently done in industry practice. They also show which requirements arise from the current approaches and thus motivate the need for a method to systematically plan EA transformation.

\subsubsection{Company A}

Company A provides IT outsourcing services and banking solutions. The primary product is a banking platform which is offered to private and universal banks. The company focuses on three main fields, namely application development, application management and operations, and therefore offers an integrated portfolio to its customers. The application development division is responsible for the development 
of the banking platform which is described by an application architecture model, an IT architecture model, and an operating model.

Major challenges within the architectural development plan are the coordination of activities of development teams and assurance that all dependencies are addressed and that milestones of integration and development activities are met simultaneously. If, for example, a component of an application needs an interface to a component of another application at a certain time for a certain milestone (e.g. test or release), it has to be assured that both components are available at that very point in time. This simple example grows very complex as the banking platform comprises over 200 applications, each consisting of a multitude of components that each has its own lifecycle as well as precursor and successor relationships.

The following questions are crucial to the architectural development process:

- How can the necessary changes for achieving the desired to-be state be identified?

- How can the necessary changes be coordinated?

- How can transformation be decomposed into project activities?

- How can the necessary development activities be bundled in order to be integrated into one release?

- Who should be responsible for which activity that has to be performed for answering these questions?

\subsubsection{Company B}

Company B is a globally operating bank based in Switzerland. During recent decades, mergers led to an increasing complexity of its application landscape. Architecture management is carried out by more than 90 architects and comprises architecture governance which is enforced in individual information system development projects. However, while IT architecture is strong in the bank's home country, the bank has to face challenges due to heterogeneous local solutions in almost every other country.

In order to enable better management of the heterogeneous application landscape, an EA project is currently being conducted. The project focuses on an integrated view on the different solutions the IT departments offer to the company's operating departments worldwide. Solutions, in this case, denote bundles of product components configured for a certain application scenario. The intended integrated view should also enable solution roadmap planning, i.e. the continuous development of the contained components. Therefore, the following questions need to be answered:

- Which projects affect which lifecycle planning of a certain solution?

- Does postponing of a project affect the lifecycle planning of a certain solution?

- Which requirements will be addressed in which project for which release?

\subsubsection{Implications for Method Construction}

Although the two case studies reveal different wordings, the central questions aim at similar challenges which need to be encountered. This leads to general requirements concerning EA planning. Hence, a comprehensive method that supports EA planning must respect the following requirements: 
- EA models represent the changes of enterprise artifacts required by stakeholders. Therefore, at least (temporal) successor relationships and lifecycles need to be captured in one or several EA to-be models for one or several points in time.

- Since there will be alternative solutions in most cases, alternatives need to be evaluated.

- Actual project activities can be derived from EA to-be models.

- EA models reflect the interdependencies between the elements, i.e. the enterprise artifacts, as well as between their lifecycles.

In this paper, however, we focus on the process of EA planning (cf. 3.1) ${ }^{2}$. Such a process needs to respect the aforementioned model-related requirements, although it does not address them directly.

\subsection{Scientific Need}

Up to now only a few approaches for EA planning exist. While there are various contributions dealing with related questions, none of the existing approaches addresses EA planning from business to IT covering artifact relationships in semi-formal models and/or addressing model dynamics.

Historically, the topic evolved from strategic IS (information systems) planning which was firstly addressed by King in 1978 [24]. King proposes a process to design a management information system in accordance to the strategy of a corporation or government agency. As markets, organizational structures and system landscapes added more complexity to the matter of strategic planning and the alignment of business and IT, this approach as well as similar contributions were evolutionary refined. Strategic enterprise-wide information management [25] and more institutionalized IS planning processes became an issue in the 1990ies [26]. A prominent example for IS planning methods is IBM's Business System Planning (BSP) [27]. BSP aims to (re-) group IT functionalities according to data use and thereby identify application candidates with high integration intensity, but limited interfacing to other applications.

IS planning and EA planning differ in their approach, goal, and scope. While IS planning is rather technology driven and refers to the planning of systems (What IS do we need?), EA adopts a broader perspective and straightly integrates a business view on IS (What do we do now and what do we want to do? What information is needed to conduct our business in the future?) [28]. The availability of new architectural paradigms, such as service orientation, requires EA planning to focus on supplying information to stakeholders in order to support change projects. Therefore also in EA related approaches for planning were developed e.g. by Spewak (the wedding cake model) [28, 29], Pulkkinen and Hirvonen [30, 31], Op't Land et al. [32] and Niemann [33]. However, the majority of research results only focus on a unidirectional planning process that aims at improving the current structure, i.e. establishing a to-be architecture. The process of transforming the current architecture into the target architecture is only considered negligibly.

Recently the works of Buckl et al. [18, 34] and Aier et al. [19] address a comprehensive modeling approach for planning purposes in an EA context. While Buckl et al. propose a set of meta model requirements for modeling temporal aspects, their

\footnotetext{
${ }^{2}$ For a discussion of method vs. (process) model see [23].
} 
proposal focuses on application landscapes [18]. However, they take into account important temporal dimensions, e.g. the time a model is created and the time a model should be valid for the past, the present and the future, as well as different variants of future models [18]. Recommendations or a framework addressing the planning process itself cannot be found in these approaches though. Aier et al. have analytically derived an EA planning process from possible planning information models [19], have analyzed existing planning processes in practice [35] and have specified necessary techniques in approaching a planning method [36]. The paper at hand will be based on this work and design a process which can be integrated into the aforementioned method (cf. section 3.3 on preliminary work).

\section{Method Foundation for Building an EA Planning Process}

\subsection{Method Engineering}

Design research aims at the design of problem-oriented artifacts like constructs, models, and methods. A method is considered as a systematic and goal-oriented procedure to solve certain problems $[37,38]$. Thus, methods provide the basis for effective and efficient procedures while (re-)engineering enterprise components like business processes, information systems or IT infrastructure in a systemic way.

A method consists of design activities whose sequence is defined by a procedure model. The produced design results of the design activities are represented by an information model. Additionally, a method consists of roles which describe the participants involved in the design activities. At the same time the inclusion of roles introduces various perspectives different stakeholders may have on the design activities. Instructions on how design results are produced and documented are provided by adequate techniques [37].

We use a process design method in order to build a process model for EA planning. Following the distinction by Winter et al. [23], the process model is the design result of the process design method, and therefore represents a result-oriented view on a problem solution. At the same time the process model serves as a description of design activities to be performed within an EA planning method, as it is described by Aier and Gleichauf [36]. This method provides an activity-oriented view on the process model and uses it as its procedure model, adding roles and other activity recommendations on how to perform EA planning in a comprehensive manner. In other words, we use a DR artifact (process design method) in order to construct a process model which serves as a part (procedure model) of another DR artifact (method).

\subsection{PROMET BPR}

In order to design the EA planning process model we use the process design method PROMET BPR (PROject METhod Business Process Redesign) [20]. PROMET BPR has been designed as a DR artifact and is therefore thoroughly documented regarding its design activities, design results, techniques, roles and information model.

PROMET BPR targets a process design project as opposed to continuous process management. Process design involves the preliminary study, macro design, micro design, and implementation. PROMET BPR defines detailed activities and results for 
each phase which are documented in [20]. However, due to space limitations in this paper, we will focus on a limited number of activities and results that appear useful in the context of a generic EA planning process. Table 1 lists the design activities and results applied here. Those design results that are italicized are only outlined while actual result diagrams or tables are produced in chapter 4 . Some activities and results can only be designed in a specific situation. Our approach, however, aims at the design of a generic EA planning process.

The preliminary study lays the foundation for the design project. An analysis of potential benefits helps to guide the whole design process. A first description of the process architecture, i.e. a process map, depicts the interdependencies of processes and provides insight into possible output and input relationships. When adapting process in a specific situation, a more detailed description of benefits is advisable. Furthermore, the identification of a process manager and/or process committee, as recommended by PROMET BPR, as well as the description of the involved business objects should be performed.

In order to align process design with customers' needs, an analysis of the customer relations and their involvement in the process should be performed at the beginning of the macro design phase. Second, a rough process vision will guide further design of the process. Therefore, general principles and basic conditions will be defined in the process framework. With regard to the necessary process management critical success factors of the process should be identified. After these preparative steps, the context of the process will be described, as a refinement of the process map from the preliminary study. This will help to identify required outputs and leads to the identification of the activities constituting the process. A list of involved IT applications completes the macro design phase.

The aims of the micro design phase are twofold: First, it aims at further refinement of the process description, i.e. the activity flows. Second, process management is prepared by refining critical success factors, performance indicators, process managers etc. As these tasks require in-depth information about specific situations of EA planning, we will not consider them in our application of PROMET BPR.

Table 1. PROMET BPR activities and results applied

\begin{tabular}{ll}
\hline Activity & Result \\
\hline Preliminary Study & \\
\hline Design process architecture & Process Map, Process List \\
Analyze potential benefits & Benefits List \\
\hline Macro Design & \\
\hline Identify customer needs and processes & Customer Relations Diagram \\
Develop process vision & Process Framework \\
Plan process for critical success factors & Critical Success Factors \\
Check and define outputs & Contextual Diagram, Outputs List \\
Redesign process flow at macro level & Activity Chain Diagram (Macro), Activities List (Macro), \\
& Index of Applications \\
\hline
\end{tabular}

Finally, the micro-designed processes are transposed from model into practical use in an implementation phase. As PROMET BPR focuses on the (re-)design, the implementation phase is neither subject to the core of the method nor to our application of it. 


\subsection{Preliminary EA Planning Process Models}

PROMET BPR aims at redesigning business processes. Thereby it is assumed that the new design is influenced by existing business processes, though the method suggests workshop and brainstorming techniques in order to enable innovative ideas. In analogy, there already exist some ideas about an EA planning process which serve as a starting point as well as a source of inspiration for redesign.

In 2009 we conducted two workshops with experts from various companies active in the field of EA. Those experts include enterprise architects, chief architects, IT architects as well as representatives from business and strategy development fields who shared their experiences as well as their ideas concerning a comprehensive EA planning process. As a result, two proposals for a process model were developed which addressed the requirements expressed by the workshop participants.

Aier and Saat conducted six expert interviews and used them to construct an extended planning process based on approaches found in literature [35]. Their findings are also taken as a basis for the process redesign tasks in the paper at hand.

Finally, the process model is intended to be integrated in a comprehensive EA planning method which is described by Aier and Gleichauf [36]. In their article, they develop a list of design results, information model requirements as well as a preliminary list of design activities. The paper at hand aims at complementing this approach in terms of the design activities and process.

\section{Construction of the Process Model for EA Planning}

\subsection{Preliminary Study Phase}

Redesigning a process requires an estimation what potential benefits will be generated. Therefore, the first step in the preliminary study is a benefits analysis. It helps to clarify the goals of the redesign project and provides economic arguments for the project at the same time. In order to identify the processes that are relevant to the process that is to be redesigned, a process map is established in the preliminary study. The map depicts the main processes that exchange inputs/outputs with the process of interest. As the map is further refined in the macro design phase as a contextual diagram, we abstain from presenting the process map at this point.

Benefits List. In general, EA aims at enabling and ensuring transparency, consistency, flexibility and finally agility throughout the organization [39]. The EA planning process will ensure transparency and consistency by enabling coordinated further development of business and IT structures by using EA models. Moreover it will help to prioritize necessary development projects, i.e. to optimize budget and resource allocations and thereby realize global optima instead of local (project) optima. Being based on EA models and intertwined with EA management processes, the EA planning process will enforce the application of EA standards and principles in development projects. This will in turn improve the cost/benefit ratio of EA as the costs of information gathering and modeling will generate benefit for planning tasks: Applying the EA planning process will provide a consolidated information base for release management, project and program management. 


\subsection{Macro Design Phase}

\subsubsection{Customer Relations Diagram}

PROMET BPR suggests that customer processes and customers' needs are identified in order to gain insight into the customer relations and enhance the value of outputs. While customers can easily be identified as extra-organizational customers in a provider-customer relationship, from a process' point of view also intra-organizational customers are relevant. These customers might more precisely be called stakeholder of the process. In the context of EA, stakeholder-oriented approaches have been presented e.g. by Kurpjuweit and Winter [40]. Stakeholders of the EA planning process might include the management body, enterprise architects or IT architects.

\subsubsection{Process Framework}

The cornerstones of the process on which the detailed design will be based are captured in the process framework. This includes assumptions about the process to be designed and about its surrounding processes. In the case of the EA planning process it is assumed that requirements as input for EA planning are provided by external processes, e.g. by requirements management. Further assumptions for the process framework are highly dependent from the actual situation of application.

\subsubsection{Critical Success Factors}

With regard to the necessary process management critical success factors of the process are identified. Ylimäki has presented a list of critical success factors for EA [41]. Among them, e.g. the overall maturity of the EA discipline and its penetration throughout the organization is critical. Especially more advanced EA processes like EA planning require a rather high EA maturity level.

\subsubsection{Contextual Diagram}

Before planning actual activities constituting the process a definition of the required outputs is necessary. Therefore, a contextual diagram describes input and output flows with other processes. This sets a basic framework for the process to be designed (figure 1).

The EA planning process is one of several EA management processes, complementing EA as-is documentation or maintenance processes as well as EA analysis processes. EA planning is driven by development requirements from the different sub-architectures. Therefore it receives input from processes in the fields of product portfolio management, business process management, application portfolio management, IT infrastructure management and the like. As the planning process is based on EA models, information about as-is models and condensed information from EA analysis is also needed. Besides that, strategic principles from business and IT strategy processes guide the EA planning process. Main outputs of the planning process are to-be models of future architecture states as well as project descriptions about development projects that will implement the planned enhancements. Those project proposals are accompanied by EA principles that are developed within the EA management processes and distributed into implementation processes via EA planning. As EA principles are main components of EA (cf. definition of EA in section 1) their 


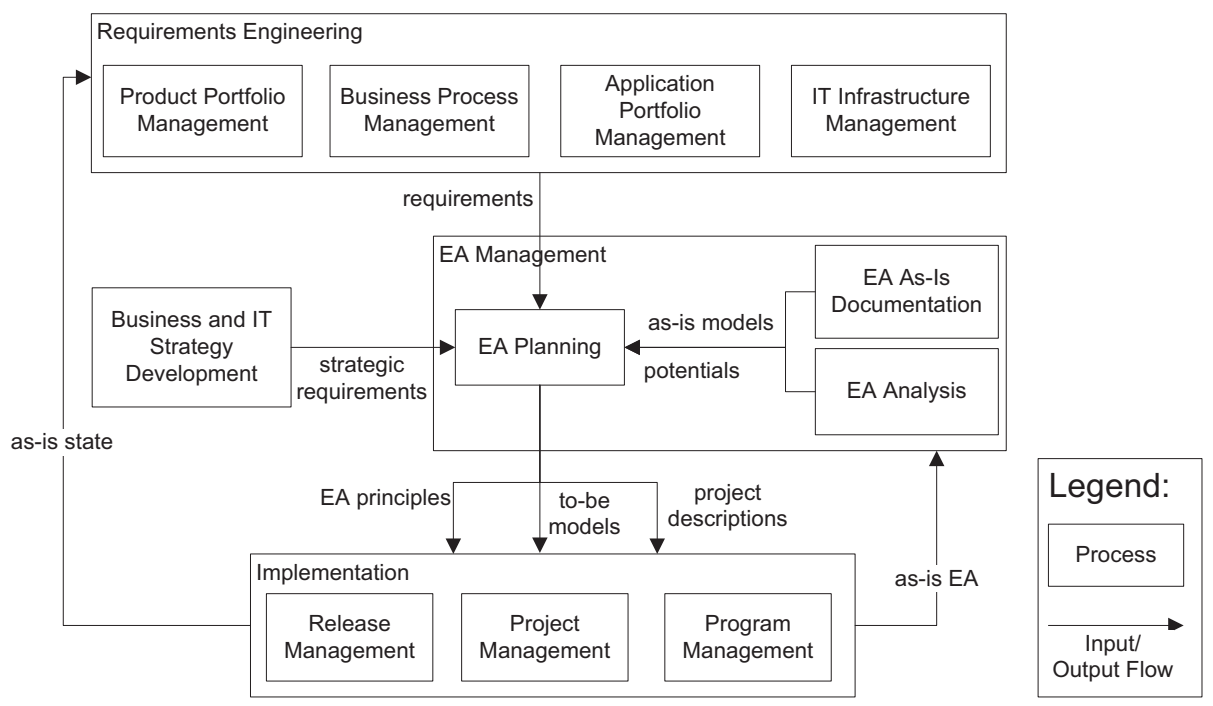

Fig. 1. Contextual diagram of the EA planning process

deduction and dissemination requires for adequate processes. However, in this paper this is not discussed in detail. The actual implementation is then done by release management, project management and program management processes. From there, information about the current state of EA is feed back to EA management and to sub-architectures' management processes.

\subsubsection{Outputs List}

As already indicated in the contextual diagram, outputs are exchanged between the EA planning process and other processes. In addition, intermediate outputs between the activities within the EA planning process itself are relevant in order to identify process activities. The main output of the EA planning process are project proposals that roughly describe which development tasks are necessary (cf. [36]). These proposals might also include an assessment of which tasks are more relevant than others and which should be performed in conjunction or in parallel. As intermediate outputs the EA planning process will generate a new EA vision (or update an existing one) and one or several EA roadmaps. Most likely the planning process will generate alternative to-be models of the EA, so an assessment framework as well as the assessed to-be models themselves will be outputs of the process. As described in the EA planning method [36], the process will in detail produce a list of model elements to be changed, a list of interdependencies between model elements within and between models as well as a list of predecessor and successor relationships of the model elements.

As already mentioned in the contextual diagram, EA standards and principles are developed and their compliance is controlled by EA management processes. EA planning in particular gathers and adapts EA principles in order to transfer them to implementation processes. 


\subsubsection{Activities}

The main step of the macro design phase is flow planning which takes results of the contextual diagram as well as the list of outputs and derives the actual tasks involved in the process, their sequence and who performs them. The activity chain diagram (figure 2) depicts the activity flow. A detailed description including involved roles is presented in the list of activities below (table 2).

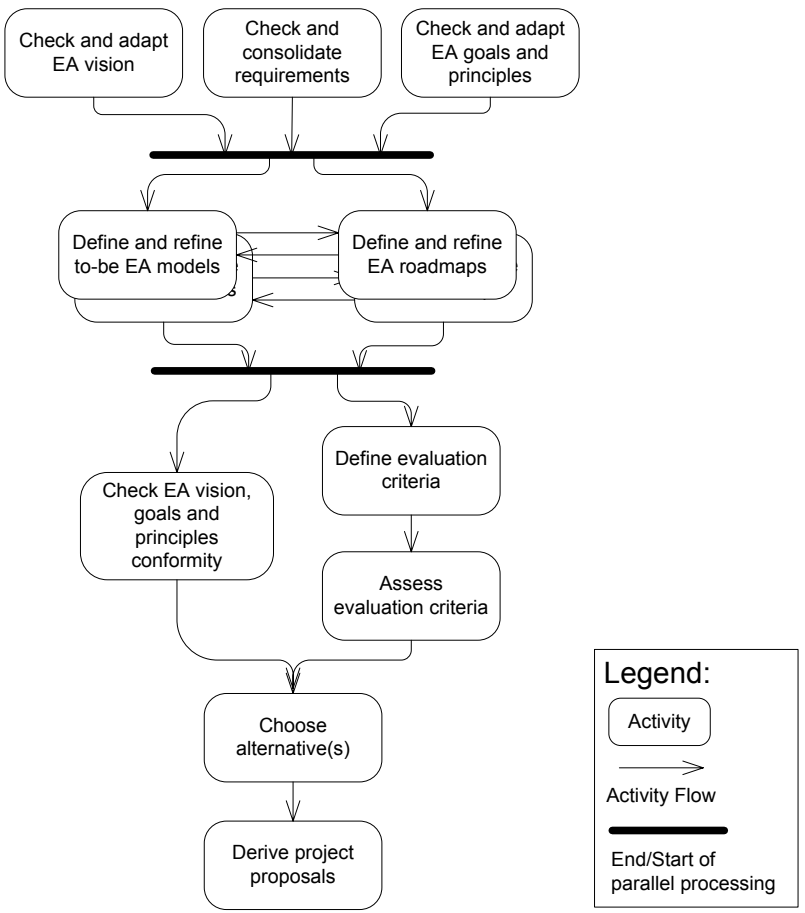

Fig. 2. Activity Chain Diagram

Table 2. Activities List

\begin{tabular}{|c|c|c|}
\hline Activity & Description & Roles \\
\hline $\begin{array}{l}\text { Check and adapt EA } \\
\text { vision }\end{array}$ & $\begin{array}{l}\text { The EA vision is defined in the EA management } \\
\text { processes and/or in the business and IT strategy } \\
\text { development. EA planning uses it as an input and } \\
\text { guideline for its planning activities. }\end{array}$ & Enterprise architect \\
\hline $\begin{array}{l}\text { Check and consolidate } \\
\text { requirements }\end{array}$ & $\begin{array}{l}\text { Requirements are gathered in the various partial } \\
\text { architectures, such as IT infrastructure or product } \\
\text { development processes. EA planning uses them } \\
\text { as an input. }\end{array}$ & $\begin{array}{l}\text { Business and IT } \\
\text { architects }\end{array}$ \\
\hline $\begin{array}{l}\text { Check and adapt EA } \\
\text { goals and principles }\end{array}$ & $\begin{array}{l}\text { EA goals and principles are defined in the EA } \\
\text { management processes. EA planning uses them } \\
\text { as an input and guideline for its planning activities. }\end{array}$ & $\begin{array}{l}\text { Enterprise architect, } \\
\text { business }\end{array}$ \\
\hline
\end{tabular}


Table 2. (Continued)

\begin{tabular}{lll}
\hline Activity & Description & Roles \\
\hline $\begin{array}{l}\text { Define and refine to-be } \\
\text { EA models }\end{array}$ & $\begin{array}{l}\text { Snapshots of future states of the enterprise } \\
\text { architecture are established (partial architecture } \\
\text { snapshots might be consolidated). Alternatives } \\
\text { are depicted and aligned with roadmap plans. }{ }^{*}\end{array}$ & $\begin{array}{l}\text { Enterprise architect, } \\
\text { business and IT } \\
\text { architects }\end{array}$ \\
\hline $\begin{array}{l}\text { Define and refine EA } \\
\text { roadmaps }\end{array}$ & $\begin{array}{l}\text { Alternative EA roadmaps are depicted and } \\
\text { aligned with to-be models. }\end{array}$ & $\begin{array}{l}\text { Enterprise architect, } \\
\text { business and IT } \\
\text { architects }\end{array}$ \\
\hline Define evaluation criteria & $\begin{array}{l}\text { In order to assess alternatives and guide a } \\
\text { decision process, evaluation criteria are defined. }\end{array}$ & Enterprise architect \\
\hline Check EA vision, goals & $\begin{array}{l}\text { Chosen alternatives need to adhere to EA vision, } \\
\text { and principles conformity } \\
\text { goals and principles. Therefore, alternatives are } \\
\text { checked against their conformity. }\end{array}$ & Enterprise architect \\
\hline Assess evaluation criteria. & $\begin{array}{l}\text { Assessment of alternatives may e.g. include the } \\
\text { consideration of costs, benefits and risks. }\end{array}$ & $\begin{array}{l}\text { Enterprise architect, } \\
\text { management (sponsor) }\end{array}$ \\
\hline Choose alternative(s) & $\begin{array}{l}\text { Choose the favored alternative on the basis of } \\
\text { evaluation criteria. }\end{array}$ & $\begin{array}{l}\text { Enterprise architect, } \\
\text { management (sponsor) }\end{array}$ \\
\hline Derive project proposals & $\begin{array}{l}\text { One or more project proposals are derived. It } \\
\text { might be useful to have alternative project } \\
\text { proposals for different future scenarios. }\end{array}$ & $\begin{array}{l}\text { Enterprise architect, } \\
\text { management (sponsor) }\end{array}$ \\
\hline
\end{tabular}

\section{Evaluation}

As already mentioned above, preliminary considerations about an EA planning process were incorporated in the application of process (re-)design using PROMET BPR. Among those considerations practical experiences at company A, which has already been presented in chapter 2, were accounted for. At the same time, the actual application of the process model at the company serves as an evaluation.

The planning activities at the company aim at the further development of their core product, a banking platform, which consists of various applications, interfaces and middleware components. As the company also provides the hosting of the platform, also hardware issues are important.

Requirements that guide the further development of the banking platform are gathered in two ways. On the one hand, high level guidelines for the general development vision of the platform are established by a superordinate planning team. These guidelines correspond to general EA goals and principles that are continuously adapted and updated. On the other hand, requirements for the development of the individual components and sub-architectures are collected separately.

Partial architecture roadmaps are defined following the general EA guidelines that are grouped by functional domains. The roadmaps consist of models representing snapshots of the desired architecture for up to three points in time in the future, taking into account existing vendor specific constraints if applicable. Individual component development plans are then integrated into these roadmaps. The coordination between high level guidelines, partial roadmaps and detailed to-be models is ensured by an 
organizational structure that defines roles of lead architects being responsible for the partial architectures (business, applications, IT, operations, and security) as well as roles of domain architects who are responsible for functional domains. While domain architects control the development and realization of high level roadmaps, lead architects drive and ensure the further development of components taking detailed restrictions into account. In joint workshops all parties consolidate their plans. This also improves the conformity with EA goals and principles. Possible alternatives are discussed and evaluated in these workshops.

In order to determine a sequence of tangible development activities general milestones and components to be developed are defined. Afterwards, the development phases of the elements' lifecycles are planned in detail, i.e. in terms of specification and testing phases. Upon those specifications a rough project program schedule can be defined. Finally, on the basis of the project outlines actual project planning is enabled. For that purpose, the project proposals can be enriched with information about costs, quality metrics, staff, risks, and resources.

The application at company A shows that the presented EA planning process is indeed useful in practice. Of course, a lot of more details need to be added to the process model in order to be actually implemented. For example, the process customers' needs play an important role regarding the coordination of possible alternative roadmaps or to-be models. At company A process customers are e.g. the teams of the lead architects which are affected by EA principles. By incorporating them into the planning activities, their needs are addressed. At the same time, these organizational structures constitute an important critical success factor for the EA planning process.

\section{Discussion and Outlook}

The aim of our research has been to build a process for EA planning as a DR artifact. In order to systematically build this process we have used the PROMET BPR method for process (re-) design. Derived from desired design results we have described the necessary design activities and linked these activities in the EA planning process. The resulting process uses alternative to-be models that represent different points in time and enables the evaluation of alternatives as well as the derivation of project activities. Thus it respects the requirements derived in section 2.1.3.

In contrast to a typical application of PROMET BPR our planning process stays on a more generic level and is not build for a specific situation. However, the application of the process in an industry case demonstrates how this generic process can be further detailed. This leads to the question of situational methods [42, 43]: The distinction of a limited number of well defined situations described by certain project types and contingency factors [44] could guide a configuration of a more detailed planning process. While some contributions $[45,46]$ have made first steps in describing and identifying situations for EA management we did not yet comprehend the relationships of EA management goals, EA realization approaches, enterprise engineering goals, and planning approaches. Thus our approach still lacks the concept of situation.

Although the application of our process illustrates the usefulness of our artifact in this specific situation, we could not show the superiority of our approach. This is due the lack of concepts for scientific progress of DR artifacts. While Aier and Fischer 
[47] propose criteria for assessing the progressivity of a design research artifact their criteria are still heavily dependent from the specific purpose and scope of the artifact and thus from the situation of application.

Finally we demonstrate in our paper how DR artifacts (e.g. methods) can be employed in order to build new - more specific but still applicable in a number of situations - DR artifacts. This leads to the question, whether design research (as an engineering approach [3]) needs a more structured catalogue of design knowledge. While Gericke [48] and Vaishnavi and Kuechler [49] discuss this question on a meta level under the term DSR patterns, Shaw [50] presents an analysis of mature engineering disciplines. Among other points she finds that mature engineering disciplines (e.g. mechanical engineering) all provide a commonly accepted, well structured knowledge base (e.g. [51]) that provides guidance especially for more routine like engineering tasks. Process design or the assignment of organizational responsibilities to certain tasks in a process represents such routine like engineering tasks. One of the major obstacles for providing such a knowledge base, however, is the form of documentation for these mostly complex DR artifacts. First approaches to this issue may be found in the work of Frank [52] who proposes a structure for description of artifacts.

\section{References}

1. March, S.T., Smith, G.F.: Design and Natural Science Research on Information Technology. Decision Support Systems 15, 251-266 (1995)

2. vom Brocke, J., Buddendick, C.: Reusable Conceptual Models - Requirements Based on the Design Science Research Paradigm. In: Proceedings of the First International Conference on Design Science Research in Information Systems and Technology (DESRIST), pp. 576-604 (2006)

3. Hevner, A.R., March, S.T., Park, J., Ram, S.: Design Science in Information Systems Research. MIS Quarterly 28, 75-105 (2004)

4. Gregor, S., Jones, D.: The Anatomy of a Design Theory. Journal of the Association for Information Systems 8, 312-335 (2007)

5. Venable, J.: The Role of Theory and Theorising in Design Science Research. In: Proceedings of the 1st International Conference on Design Science in Information Systems and Technology (DESRIST 2006), pp. 1-18. Claremont Graduate University, Claremont (2006)

6. Walls, J.G., Widmeyer, G.R., El Sawy, O.A.: Building an Information System Design Theory for Vigilant EIS. Information Systems Research 3, 36-59 (1992)

7. Cross, N.: Designerly Ways of Knowing: Design Discipline Versus Design Science. Design Issues 17, 49-55 (2001)

8. Winter, R.: Design Science Research in Europe. European Journal of Information Systems 17, 470-475 (2008)

9. IEEE: IEEE Recommended Practice for Architectural Description of Software Intensive Systems (IEEE Std 1471-2000). IEEE Computer Society, New York (2000)

10. Tyler, D.F., Cathcart, T.P.: A structured Method for Developing Agile Enterprise Architectures. In: International Conference on Agile Manufacturing (ICAM 2006), Norfolk, Virginia, USA, pp. 1-8 (2006) 
11. Winter, R., Fischer, R.: Essential Layers, Artifacts, and Dependencies of Enterprise Architecture. Journal of Enterprise Architecture 3, 7-18 (2007)

12. Jonkers, H., Lankhorst, M.M., Doest, H.W.L., Arbab, F., Bosma, H., Wieringa, R.J.: Enterprise architecture: Management tool and blueprint for the organisation. Information Systems Frontiers 8, 63-66 (2006)

13. Lankhorst, M.: Enterprise Architecture at Work: Modelling, Communication and Analysis. Springer, Berlin (2005)

14. Schelp, J., Winter, R.: Language Communities in Enterprise Architecture Research. In: Diversity in Design Science - Proceedings of the 4th Conference on Design Science Research in Information Systems and Technologies (DESRIST 2009), Philadelphia, PA, USA, May 7-9, pp. 1-10. ACM, Philadelphia (2009)

15. Lindström, L., Johnson, P., Johansson, E., Ekstedt, M., Simonsson, M.: A survey on CIO concerns - Do enterprise architecture frameworks support them? Information Systems Frontiers 8, 81-90 (2006)

16. Frank, U.: Perspective Enterprise Modeling (MEMO) - Conceptual Framework and Modeling Languages. In: 35th Hawaii International Conference on System Sciences (2002)

17. Jonkers, H., Lankhorst, M., van Buuren, R., Hoppenbrouwers, S., Bonsangue, M., van der Torre, L.: Concepts for Modelling Enterprise Architectures. International Journal of Cooperative Information Systems 13, 257-287 (2004)

18. Buckl, S., Ernst, A.M., Matthes, F., Schweda, C.M.: An Information Model for Managed Application Landscape Evolution. Journal of Enterprise Architecture 5, 12-26 (2009)

19. Aier, S., Gleichauf, B., Saat, J., Winter, R.: Complexity Levels of Representing Dynamics in EA Planning. In: Proceedings of the 5th International Workshop on Cooperation \& Interoperability - Architecture \& Ontology (CIAO! 2009), pp. 55-69. Springer, Amsterdam (2009)

20. IMG: PROMET BPR: Method for Business Process Redesign, Release 2.0. Information Management Group/Institute of Information Management, University of St. Gallen, St. Gallen (1997)

21. Rossi, M., Sein, M.K. (eds.): Design Research Workshop: A Proactive Research Approach. IRIS Association, Haikko (2003)

22. Peffers, K., Tuunanen, T., Gengler, C.E., Rossi, M., Hui, W., Virtanen, V., Bragge, J.: The Design Science Research Process: A Model for Producing and Presenting Information Systems Research. In: 1st International Conference on Design Science in Information Systems and Technology (DESRIST), Claremont, CA, pp. 83-106 (2006)

23. Winter, R., Gericke, A., Bucher, T.: Method versus Model - Two Sides of the Same Coin? In: Advances in Enterprise Engineering III: 5th International Workshop, CIAO! 2009, and 5th International Workshop, EOMAS 2009, held at CAiSE 2009, pp. 1-15. Springer, Amsterdam (2009)

24. King, W.: Strategic Planning for Management Information Systems. MIS Quarterly 2, 27-37 (1978)

25. Targowski, A.: The architecture and planning of enterprise-wide information management systems. Idea Group Publishing, Harrisburg (1990)

26. Eliot, L.B.: Information systems strategic planning. Computer Technology Research Corporation, Charleston (1991)

27. IBM: Business Systems Planning: Information Systems Planning Guide, vol. 1. IBM, Atlanta (1984)

28. Spewak, S.H., Hill, S.C.: Enterprise Architecture Planning - Developing a Blueprint for Data, Applications and Technology. John Wiley \& Sons, New York (1993) 
29. Spewak, S.H., Tiemann, M.: Updating the Enterprise Architecture Planning Model. Journal of Enterprise Architecture 2, 11-19 (2006)

30. Pulkkinen, M., Hirvonen, A.: EA Planning, Development and Management Process for Agile Enterprise Development. In: Proceedings of the 38th Annual Hawaii International Conference on Systems Sciences (HICSS-38), p. 223.223 (221-210). IEEE Computer Society, Los Alamitos (2005)

31. Pulkkinen, M.: Systemic Management of Architectural Decisions in Enterprise Architecture Planning. Four Dimensions and Three Abstraction Levels. In: Proceedings of the 39th Annual Hawaii International Conference on System Sciences (HICSS-39), pp. 179a (171-179). IEEE Computer Society Press, Honolulu (2006)

32. Op 't Land, M., Proper, E., Waage, M., Cloo, J., Steghuis, C.: Enterprise Architecture Creating Value by Informed Governance. Springer, Berlin (2009)

33. Niemann, K.D.: From Enterprise Architecture to IT Governance. Elements of Effective IT Management. Vieweg, Wiesbaden (2006)

34. Buckl, S., Ernst, A., Matthes, F., Schweda, C.M.: An Information Model for Landscape Management - Discussing Temporality Aspects. In: Proceedings of the 3rd Workshop on Trends in Enterprise Architecture Research (TEAR 2008), Sydney (2008)

35. Aier, S., Saat, J.: Understanding Processes for Model-based Enterprise Transformation Planning. International Journal of Internet and Enterprise Management 7 (2010)

36. Aier, S., Gleichauf, B.: Application of Enterprise Models for Engineering Enterprise Transformation. Enterprise Modelling And Information Systems Architectures forthcoming (2010)

37. Braun, C., Wortmann, F., Hafner, M., Winter, R.: Method Construction - A Core Approach to Organizational Engineering. In: Applied Computing 2005, Proceedings of the 2005 ACM Symposion on Applied Computing, pp. 1295-1299. ACM Press, New York (2005)

38. Brinkkemper, S.: Method Engineering: Engineering of Information Systems Development Methods and Tools. Information and Software Technology 38, 275-280 (1996)

39. Dietz, J.L.G.: Enterprise Ontology - Theory and Methodology. Springer, Heidelberg (2006)

40. Kurpjuweit, S., Winter, R.: Concern-oriented Business Architecture Engineering. In: Proceedings of the 24th Annual ACM Symposium on Applied Computing (SAC), pp. 265-272. Honolulu, Hawaii (2009)

41. Ylimäki, T.: Potential Critical Success Factors for Enterprise Architecture. Journal of Enterprise Architecture 2, 29-40 (2006)

42. Harmsen, A.F., Brinkkemper, S., Oei, H.: Situational Method Engineering for Information System Project Approaches. In: Methods and Associated Tools for the Information Systems Life Cycle, pp. 169-194. North-Holland, Amsterdam (1994)

43. Karlsson, F., Ågerfalk, P.J., Hjalmarsson, A.: Method Configuration with Development Tracks and Generic Project Types. In: 6th CAiSE/IFIP8.1 International Workshop on Evaluation of Modeling Methods in System Analysis and Design (EMMSAD 2001), Interlaken, Switzerland (2001)

44. Bucher, T., Klesse, M., Kurpjuweit, S., Winter, R.: Situational Method Engineering - On the Differentiation of "Context" and "Project Type". In: Situational Method Engineering Fundamentals and Experiences, pp. 33-48. Springer, Boston (2007)

45. Aier, S., Riege, C., Winter, R.: Classification of Enterprise Architecture Scenarios - An Exploratory Analysis. Enterprise Modelling and Information Systems Architectures 3, 14-23 (2008) 
46. Leppänen, M., Valtonen, K., Pulkkinen, M.: Towards a Contingency Framework for Engineering an Enterprise Architecture Planning Method. In: Proceedings of the 30th Information Systems Research Seminar in Scandinavia (IRIS 2007), Tampere, Finland (2007)

47. Aier, S., Fischer, C.: Scientific Progress of Design Research Artefacts. In: Proceedings of the 17th European Conference On Information Systems (2009)

48. Gericke, A.: Analysis of Design Science Research Patterns from an Engineering Perspective. In: Proceedings of the IADIS International Conference Information Systems 2009 (IS 2009), pp. 64-72 (2009)

49. Vaishnavi, V.K., Kuechler, W.: Design Science Research Methods and Patterns: Innovating Information and Communication Technology. Auerbach Publications, New York (2007)

50. Shaw, M.: Prospects for an Engineering Discipline of Software. Software, IEEE 7, 15-24 (1990)

51. Dubbel, H., Kuttner, K.H., Beitz, W.: Dubbel. Handbook of Mechanical Engineering. Springer, Berlin (1994)

52. Frank, U.: Towards a Pluralistic Conception of Research Methods in Information Systems Research. Institut für Informatik und Wirtschaftsinformatik (ICB), Universität DuisburgEssen, Essen (2006) 